\title{
Molten Salt Destruction of Energetic Material Wastes as an Alternative to Open Burning
}

\author{
R. S. Upadhye \\ C. O. Pruneda \\ B. E. Watkins
}

This paper was prepared for submittal to Chemistry for Protection of the Environment Poland

September 18-22, 1995

September, 26, 1995

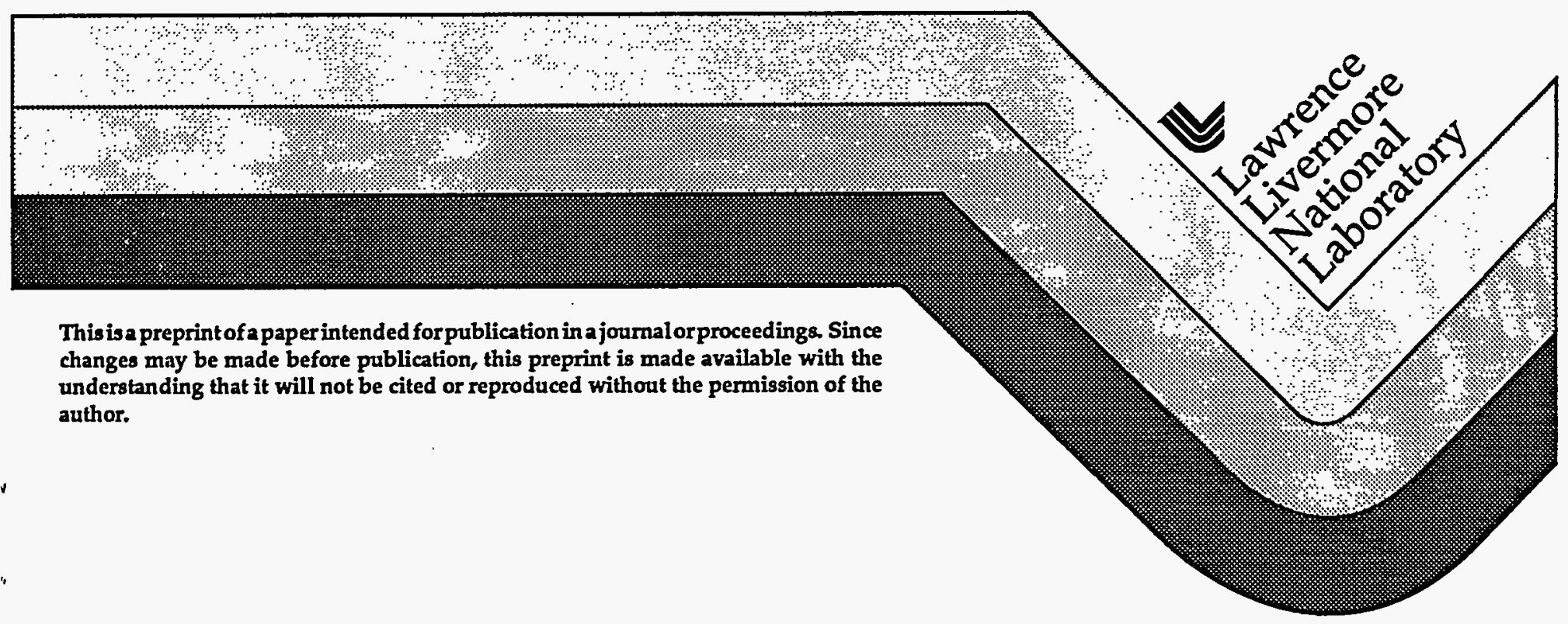




\section{DISCLAIMER}

This document was prepared as an account of work sponsored by an agency of the United States Government. Neither the United States Government nor the University of California nor any of their employees, makes any warranty, express or implied, or assumes any legal liability or responsibility for the accuracy, completeness, or usefulness of any information, apparatus, product, or process disclosed, or represents that its use would not infringe privately owned rights. Reference herein to any specific commercial product, process, or service by trade name, trademark, manufacturer, or otherwise, does not necessarily constitute or imply its endorsement, recommendation, or favoring by the United States Government or the University of California. The views and opinions of authors expressed herein do not necessarily state or reflect those of the United States Government or the University of California, and shall not be used for advertising or product endorsement purposes.

This report has been reproduced directly from the best available copy.

Available to DOE and DOE contractors from the Office of Scientific and Technical Information P.O. Box 62, Oak Ridge, TN 37831

Prices available from (615) 576-8401, FTS 626-8401

Available to the public from the

National Technical Information Service

U.S. Department of Commerce

5285 Port Royal Rd., Springfield, VA 22161 


\title{
MOLTEN SALT DESTRUCTION OF ENERGETIC MATERIAL WASTES AS AN ALTERNATIVE TO OPEN BURNING
}

\author{
Ravindra S. Upadhye, César O. Pruneda, and Bruce E. Watkins
}

\begin{abstract}
The Lawrence Livermore National Laboratory in conjunction with the Energetic Materials Center ( a partnership of Lawrence Livermore and Sandia National Laboratories), is developing methods for the safe and environmentally sound destruction of explosives and propellants as a part of the Laboratory's ancillary demilitarization mission. As a result of the end of the Cold War and the shift in emphasis to a smaller stockpile, many munitions, both conventional and nuclear, are scheduled for retirement and rapid dismantlement and demilitarization. Major components of these munitions are the explosives and propellants, or energetic materials. The Department of Energy has thousands of pounds of energetic materials which result from dismantlement operations at the Pantex Plant. The Department of Defense has several hundred million pounds of energetic materials in its demilitarization inventory, with millions more added each year. In addition, there are vast energetic materials demilitarization inventories world-wide, including those in the former Soviet Union and eastern Bloc countries. Although recycling and reusing is the preferred method of dealing with these surplus materials, there will always be the necessity of destroying intractable or unusable energetic materials. Traditionally, open burn/open detonation $(\mathrm{OB} / \mathrm{OD})$ has been the method of choice for the destruction of energetic materials. Public concerns and increasingly stringent environmental regulations have made open burning and open detonation of energetic materials increasingly costly and nearly unacceptable. Thus, the impetus to develop environmentally sound alternatives to dispose of energetic materials is great.
\end{abstract}

The Molten Salt Destruction (MSD) Process has been demonstrated for the destruction of $\mathrm{HE}$ and HE-containing wastes $(1,2,3)$. MSD converts the organic constituents of the waste into non-hazardous substances such as carbon dioxide, nitrogen and water. Any inorganic constituents of the waste, such as binders and metallic particles, are retained in the molten salt. The destruction of energetic material waste is accomplished by introducing it, together with oxidant gases, into a crucible containing a molten salt, such as sodium

*This work was performed under the auspices of the U.S. Department of Energy by the Lawrence Livermore National Laboratory under contract number W-7405-ENG-48. 
carbonate, or a suitable mixture of the carbonates, chlorides or sulfates of sodium, potassium, lithium and calcium.

We destroyed the following pure component DOE and DoD explosives in the experimental in our High Explosives Applications Facility (HEAF):Ammonium Picrate, HMX, K-6, NQ, NTO, PETN, RDX, TATB, and TNT. In addition, we destroyed the following formulations: Comp-B, LX-10, LX-16, LX-17, and PBX-9404. We continued our investigation into the destruction of the liquid gun propellant XM-46 for the US Army. In all these cases, the fractions of carbon converted to $\mathrm{CO}$ and of chemically bound nitrogen converted to NOx were found to be well below $1 \%$. The details of the experiments are contained in the attached paper. In addition, we have completed construction of the next MSD unit, incorporating our advanced design. This unit, currently under installation, is nominally rated at $5 \mathrm{~kg} / \mathrm{hr}$ of $\mathrm{HMX}$.

\section{Introduction}

The Lawrence Livermore National Laboratory in conjunction with the Energetic Materials Center ( a partnership of Lawrence Livermore and Sandia National Laboratories), is developing methods for the safe and environmentally sound destruction of explosives and propellants as a part of the Laboratory's ancillary demilitarization mission. As a result of the end of the Cold War and the shift in emphasis to a smaller stockpile, many munitions, both conventional and nuclear, are scheduled for retirement and rapid dismantlement and demilitarization. Major components of these munitions are the explosives and propellants, or energetic materials. The Department of Energy has thousands of pounds of energetic materials which result from dismantlement operations at the Pantex Plant. The Department of Defense has several hundred million pounds of energetic materials in its demilitarization inventory, with millions more added each year. In addition, there are vast energetic materials demilitarization inventories world-wide, including those in the former Soviet Union and eastern Bloc countries. Although recycling and reusing is the preferred method of dealing with these surplus materials, there will always be the necessity of destroying intractable or unusable energetic materials. Traditionally, open burn/open detonation $(O B / O D)$ has been the method of choice for the destruction of energetic materials. Public concerns and increasingly stringent environmental regulations have made open burning and open detonation of energetic materials increasingly costly and nearly unacceptable. Thus, the impetus to develop environmentally sound alternatives to dispose of energetic materials is great.

The Molten Salt Destruction (MSD) Process has been demonstrated for the destruction of $\mathrm{HE}$ and HE-containing wastes(1,2,3). MSD converts the organic constituents of the waste into non-hazardous substances such as carbon dioxide, nitrogen and water. Any inorganic constituents of the waste, such as binders and metallic particles, are retained in the molten salt. The destruction of energetic material waste is accomplished by introducing it, 
together with oxidant gases, into a crucible containing a molten salt, such as sodium carbonate, or a suitable mixture of the carbonates, chlorides or sulfates of sodium, potassium, lithium and calcium. (See Figure 1 for the process flow diagram, and Figure 2 for the schematic of the experimental set-up.)

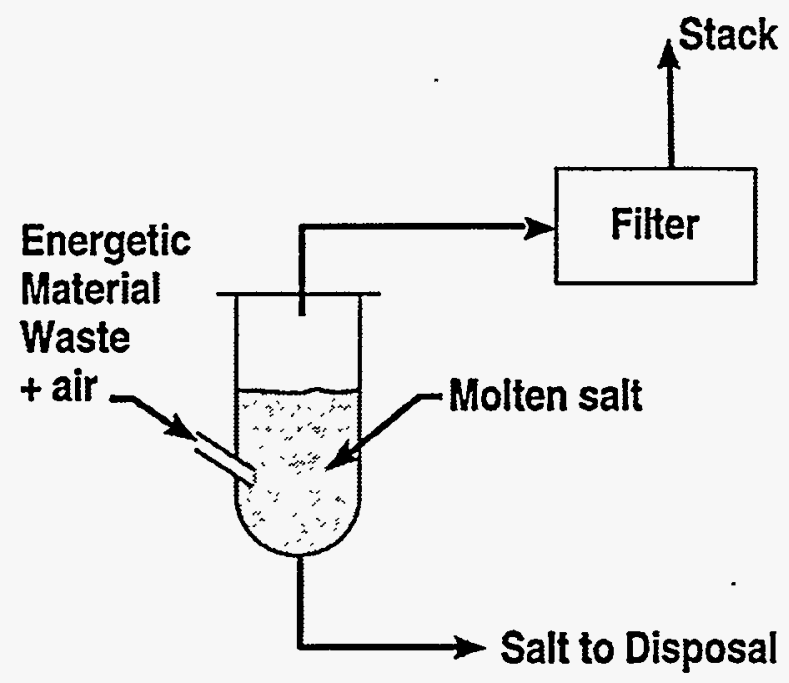

Figure 1: Process Flow Diagram

The temperature of the molten salt can be between $400^{\circ}$ to $900^{\circ} \mathrm{C}$. The organic components of the waste react with oxygen to produce carbon dioxide, nitrogen and steam. The inorganic components, in the form of "ash", are captured in the molten salt bed as a result of wetting and dissolution of the ash. Halogenated hydrocarbons in the waste (which may be present as a result of halogenated solvents in the waste, or as a result of halogenated binders for the $\mathrm{HE}$ ) generate acid gases such as hydrogen chloride during the pyrolysis and combustion processes occurring in the melt. These are scrubbed by the alkaline carbonates, producing steam and the corresponding salt, such as sodium chloride. The off-gases from the process are sent through standard off-gas clean-up processing (such as bag filters or HEPA filters) before being released to the atmosphere. At the end of the process runs, the salt is separated into carbonates, non-carbonate salts, and ash. The carbonates are recycled to the process, and the stable salts are disposed of appropriately.

LLNL has built a small-scale (about $1 \mathrm{~kg} / \mathrm{hr}$ throughput) unit to test the destruction of $\mathrm{HE}$ using the MSD process. (See Figure 3.) In addition to the high explosive HMX (octahydro- 1,3,5,7-tetranitro- 1,3,5,7-tetrazocine), we have destroyed RDX (hexahydro1,3,5-trinitro- 1,3,5-triazine), PETN (2,2-bis[\{nitoxy\}methyl]- 1,3-propanediol dinitrate), ammonium picrate, TNT (trinitrotoluene), nitroguanadine, and TATB 


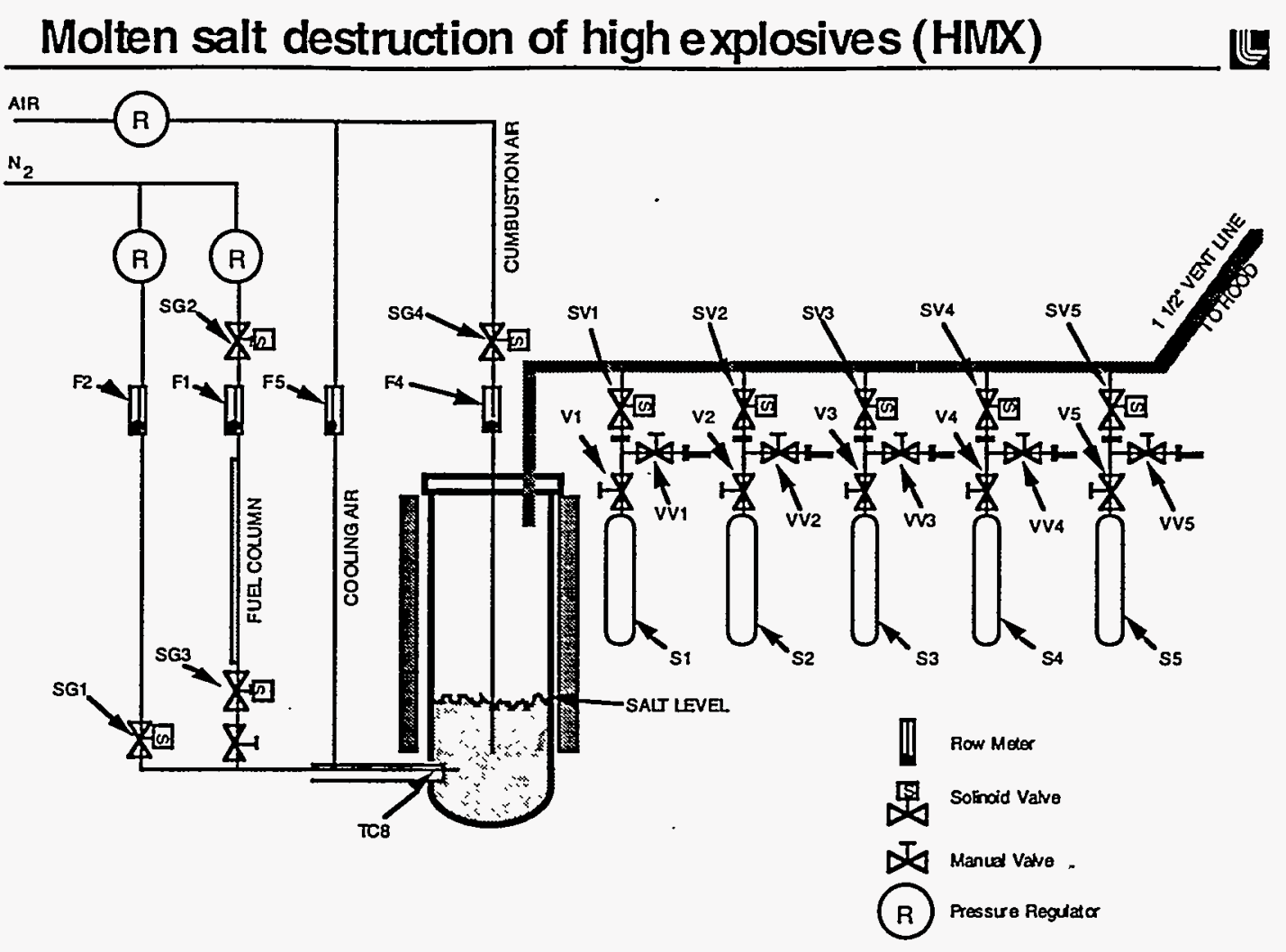

Figure 2: Experimental Schematic

(2,4,6- trinitro- 1,3,5-benzenetriamine). We have also destroyed a liquid gun propellant comprising hydroxyammonium nitrate, triethanolammonium nitrate and water. In addition to these pure components, we have destroyed a number of commonly used formulations, such as LX-10 (HMX/Viton), LX-16 (PETN/FPC 461), LX-17 (TATB/Kel F), and PBX9404 (HMX/CEF/nitrocellulose). Our experiments have demonstrated that energetic materials can be safely and effectively treated by MSD. We have also investigated the issue of steam explosions in molten salt units, both experimentally and theoretically, and concluded that steam explosions can be avoided under proper design and operating conditions. The relationship between residence time, temperature, concentration and throughputs, avoidance of back-burn, and determination of the products of combustion under different operating conditions are the key technical issues to be resolved in more controlled experiments. 


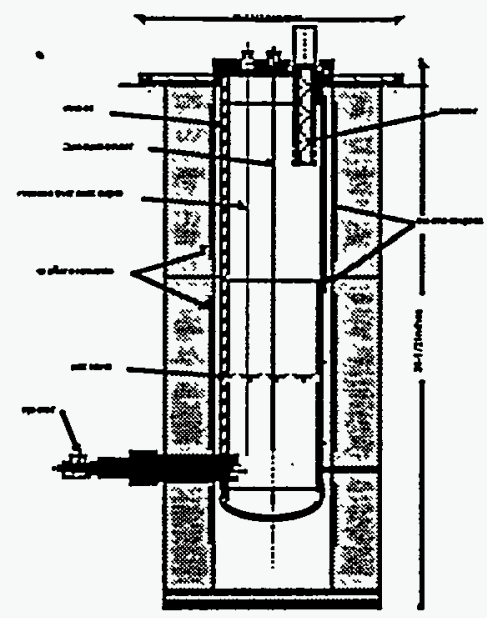

Figure 3: Details of the Crucible

\section{Technical Basis}

The molten salts are typically mixtures of alkali or alkaline earth carbonates and halides. The salts provide excellent heat transfer and reaction media, catalyze oxidation of organics, and neutralize acid gases such as hydrogen chloride by forming stable salts such as sodium chloride (4). The relatively high thermal inertia of the melt resists changes in temperature resulting from sudden changes in the feed or heat transfer.

Safety is a major consideration in any process where high explosives or wastes containing high explosives are destroyed. We have successfully and safely destroyed slurries (or solution, in case of the liquid gun propellant) of 35 weight percent energetic material ( high explosives and high explosive formulations) in water. The liquid, in addition to keeping the $\mathrm{HE}$ concentration to a safe dilution level, provides a vehicle for handling the $\mathrm{HE}$.

A typical $\mathrm{HE}$, such as $\mathrm{HMX}$, contains sufficient oxygen to propagate a steady back burn from the MSD unit to the HE reservoir without any additional oxygen. To reduce the probability of this, we developed a special nozzle design, shown in Figure 4. The key features of the nozzle are side injection of the feed into the crucible, external cooling of the feed, and introduction of a large volume of inert gas, such as nitrogen, as a carrier for the feed. The side injection, coupled with external cooling, keep the feed temperature well below $100^{\circ} \mathrm{C}$ to minimize spontaneous decomposition of the $\mathrm{HE}$. The large volume of inert carrier gas further dilutes the HE, provides a large heat capacity, and keeps the velocity of the feed inside the nozzle relatively high. As a result of all these conditions, the HE 
decomposes only inside the molten salt, and not in the feed nozzle. The high injection velocity also helps maintain a high degree of agitation and mixing inside the crucible.

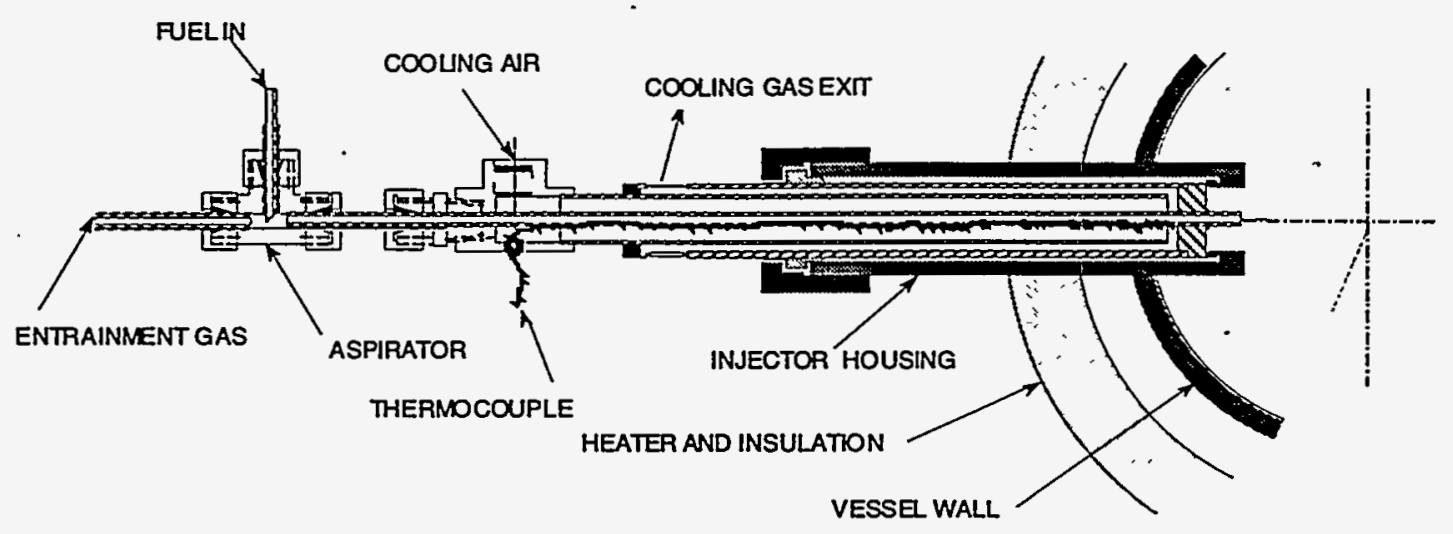

Figure 4: Details of the Nozzle

Propellants react differently from high explosives when subjected to heat. Therefore, the problem of burn-back may be more severe in some case for propellants than explosives. To avoid the possibility of back-burn, we diluted the propellant with water in the ratio of 2 parts by weight of water per one part by weight of the propellant. This dilution renders the material nonexplosive and nonflammable. This diluted mixture can be safely injected into the molten salt bath without any back-propagation.

\section{Experimental Program}

We have built an experimental unit to investigate the applicability of the molten salt destruction process to the destruction of $\mathrm{HE}$ and $\mathrm{HE}$-containing wastes. Figure 2 shows a schematic of the current experimental setup.

The crucible is made of stainless steel, which is stable in the presence of alkali carbonates. For wastes of high chlorine content, more corrosion resistant materials, such as Inconel, Hastalloy or ceramics may be necessary. The crucible has the dimensions $5.76^{\prime \prime}$ inside diameter, 6.63" outside diameter, and 24" length. It is fitted with a flange on the top and a removable injection nozzle, described earlier, on the side. Thermocouples are placed at various locations, including the crucible, the feed nozzle, and the exhaust gas outlet. The coolant gas flow is controlled so as to maintain the feed nozzle temperature under $100^{\circ} \mathrm{C}$. Gas sample bottles with manual and solenoid valves are attached to the exhaust line. The whole assembly is placed inside an explosion-proof cell, designed to withstand a detonation of up to $500 \mathrm{~g} \mathrm{HE}$ (TNT equivalent). A remotely operated TV monitor allows us to monitor the experiment without entering the cell during the experiment. All the solenoid valves controlling the sample and the feed sequences are operated remotely. The experimental data are continuously logged on a computer. 
To start an experiment, a measured amount of salt is introduced into the crucible from the top, and the top flange is secured. The sample bottles are evacuated, and the vacuum valves are closed off. The sample bottles are now ready to accept samples. The heaters are switched on, and data logging is initiated. A slurry of energetic material waste (with particle size of about $2 \mathrm{~mm}$ ) and water of desired proportions (typically $30 \mathrm{wt} \%$ solids in water) is made and kept in suspension using air driven stirrers (see Figure 3). The nozzle coolant gas is turned on to keep the feed nozzle cool. Once the salt approaches its melting point, the carrier gas in the nozzle is turned on to prevent molten salt from entering the feed nozzle. After the salt is completely molten, the oxidant feed is initiated. When the temperature of the melt reaches a desired value (typically about $750^{\circ} \mathrm{C}$ ), the system is ready for accepting the high explosive waste.

The waste to be treated is injected in to the crucible using a peristaltic pump through the side nozzle. Air is the driver gas for the feed slurry. Additional air, if needed, is introduced through the tube near the center of the crucible. The gaseous product of the crucible is sent to the vent as shown in Figure 3. A slurry of up to $500 \mathrm{~g}$ TNT equivalent. $\mathrm{HE}$ in water is fed at rates varying between $300 \mathrm{~g} / \mathrm{hr}$ to $1800 \mathrm{~g} / \mathrm{hr}$ in each run. Gas samples were collected at various intervals after steady state is obtained. A salt sample is withdrawn from the crucible at the end of the final run, and analyzed for traces of HMX. The heaters are then shut off, and the unit is allowed to cool. The entrained gas, the coolant gas and the oxidant gas are continued until the salt freezes, at which time the gas flows are shut off.

\section{Explosion Safety}

Any time a cold liquid such as water is contacted by a very hot liquid such as liquid metal or molten salt, the possibility of an explosion exists (5). We have considered two potential scenarios for explosion:

- If the outlet from the MSD reactor gets plugged or restricted, and if the liquid feed to the molten salt bath continues, the resultant pressure increase in the vessel may lead it its explosive rupture.

- The rapid heat transfer from the hot liquid to the cold liquid may give rise, temporarily, to a region of superheated liquid, which may spontaneously nucleate, resulting in an explosion (5).

The first scenario can be easily avoided by installing pressure sensors in the reactor, the lines and the auxiliary equipment, and monitoring the pressure rise continuously and carefully. Interlocks on the feed delivery system can be easily designed so that any excursion of pressure beyond the design limits stop the feed. Relief valves and rupture disks may also be used for additional safety. 
The second scenario can be dealt with by choosing proper design and operating conditions. The nozzle has been designed to disperse the feed into a stream of rapidly moving gas, thereby eliminating or reducing the probability of large slugs of cold water contacting the hot molten salt. Second, the contents of the reactor are constantly agitated by the driver gas and the air needed for oxidation. This ensures that quiescent layers of hot and cold liquids do not form in the reactor. Our analyses show that this eliminates the possibility of steam explosion in the molten salt system. We have demonstrated the safety of our specific experimental set-up by repeated injection of pure water under the molten salt bed for prolonged duration without any adverse consequences.

\section{Results and Discussion}

Gas samples were taken during the experiments, and analyzed using a gas chromatograph and mass spectrometer (GC/MS). Typical gas analyses for a number of pure component explosives and formulations are shown in Table 1.

\section{Table 1}

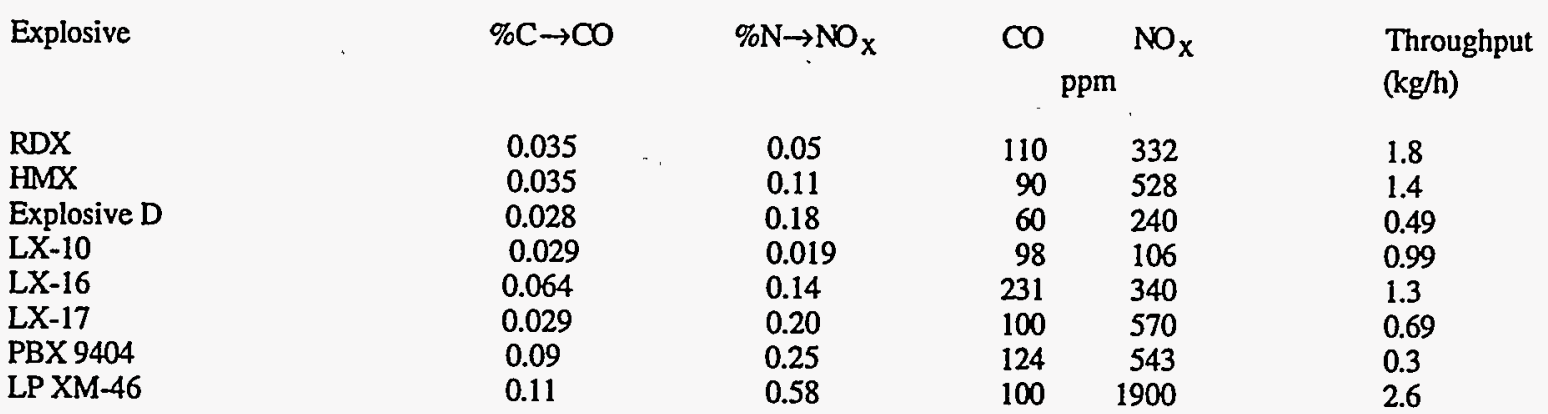

Based on the gas analyses, the following observations can be made:

1. No HCN was found in the exhaust. Since HE combustion may be accompanied by evolution of some HCN, we may infer that the $\mathrm{HCN}$, being an acid gas, was neutralized by the alkaline carbonate, producing $\mathrm{NaCN}$. This is consistent with published data regarding the effectiveness. of the molten salt as a scrubbing agent for acid gases $(5,6)$.

2. The amount of $\mathrm{NO}_{\mathrm{x}}$ and $\mathrm{CO}$ was relatively small. This indicates that the major combustion products are $\mathrm{N} 2, \mathrm{CO}_{2}$ and $\mathrm{H}_{2} \mathrm{O}$. It may be possible to reduce further the $\mathrm{NO}_{x}$ emissions by changing the operating conditions of the MSD unit (6).

The salt samples are analyzed for traces of $\mathrm{HE}$. All of the HE is expected to be fully decomposed in the molten salt. Fourier Transform-Infra Red (FT-IR) spectra of pure HEs and of molten salt into which the HE had been combusted in, respectively, show a complete absence of HE peaks in the cooled molten salt. Thus, within the detection limits of the 
method (5 ppm), no HE or propellant are detected in the salt, indicating complete oxidation. This is consistent with our expectations, given the ease of decomposition of the energetic materials at these temperatures.

\section{Conclusions and Future Work}

We have demonstrated that HEs and liquid propellants can be safely and fully destroyed using the molten salt destruction process. We are currently working on a number of improvements to the process:

- We have designed and constructed a larger unit with advanced design features. We are currently installing the unit in our High Explosives Applications Facility at LLNL. After initial shekedown, the unit will be transferred to and demonstrated at a field site (Figure 5).

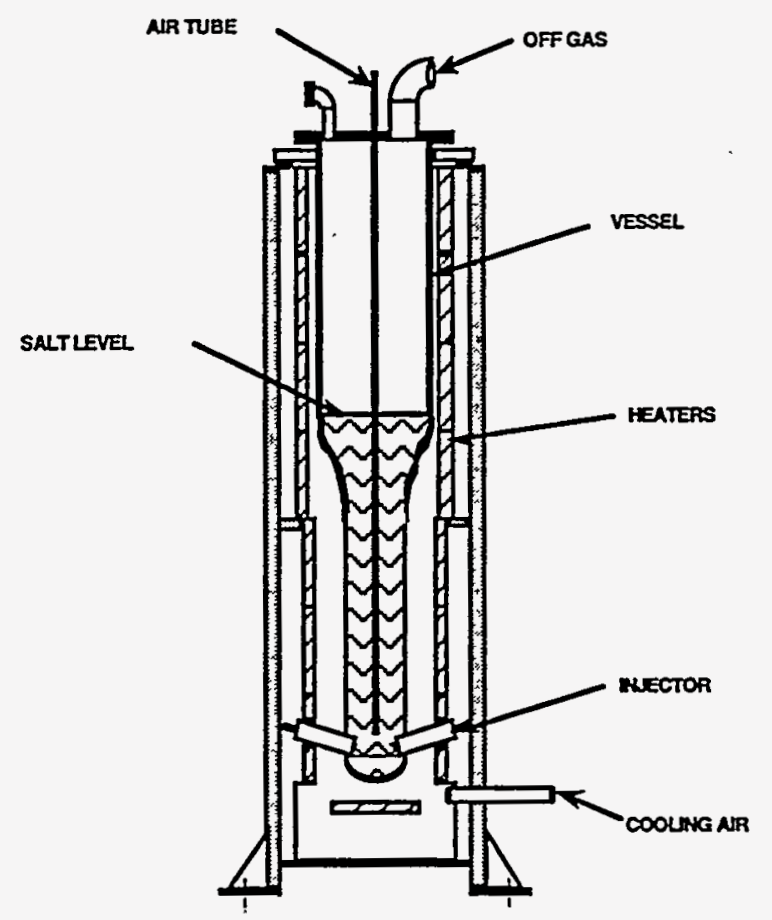

Figure 5: The Advanced Design Unit under Installation

- We are implementing an advanced nozzle design for top injection of larger particles.

- We are defining operating envelopes for a number of high explosives and formulations.

- We are developing models to study the temperature profile of a top-feed nozzle for feeding larger particles into the unit. 


\section{References}

1.Upadhye, R.S., W.A. Brummond, and C.O. Pruneda, "Destruction of High Explosives and Wastes Containing High Explosives using the Molten Salt Destruction Process", presented at the I\&EC Special Symposium, American Chemical Society, Atlanta, Georgia, September 21-23, 1992.

2. Upadhye, R.S., W.A. Brummond, and C.O. Pruneda, Destruction of High Explosives and Wastes Containing High Explosives Using the Molten Salt Destruction Process", paper V-10, presented at the "waste Management of Energetic Materials and Polymers", 23rd International Annual Conference of ICT, Karlsruhe, Germany, June 30 - July 3, 1992.

3. Brummond, W.A., R.S. Upadhye and C.O. Pruneda, "Molten Salt Destruction of Energetic Materials", U. S. Patent 5,434,335, July 18, 1995.

4. Cooper, J.F., et. al., "Molten Salt Processing of Mixed Wastes with Off-gas Condensation", presented at the 1991 Incineration Conference, Knoxville, TN, 13 May 1991. Also, UCRL-JC-107288, Lawrence Livermore National Laboratory, Livermore, CA, 1991.

5. Henry, R.E., et. al., "Large Scale Vapor Explosions", Proceedings of the Fast Reactor Safety Meeting, April 2-4, 1974, Beverly Hills, CA (NTIS Ref. No. CONF-740401P2).

6. Gay, R.L., et. al., "Treatment of Propellant and Explosive Wastes using Molten Salt Oxidation", presented at the I\&EC Special Symposium, American Chemical Society, Atlanta, Georgia, September 21-23, 1992. 
. 
Technical Information Department . Lawrence Livermore National Laboratory University of California - Livermore, California 94551

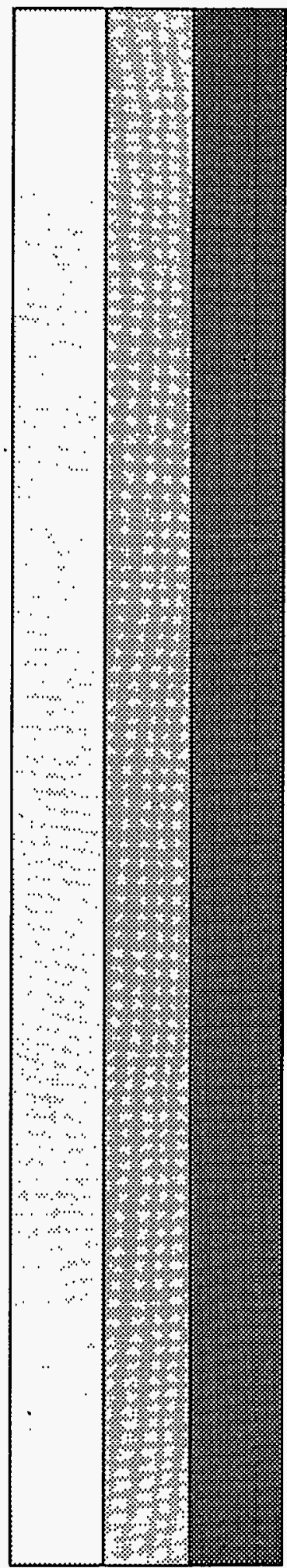

